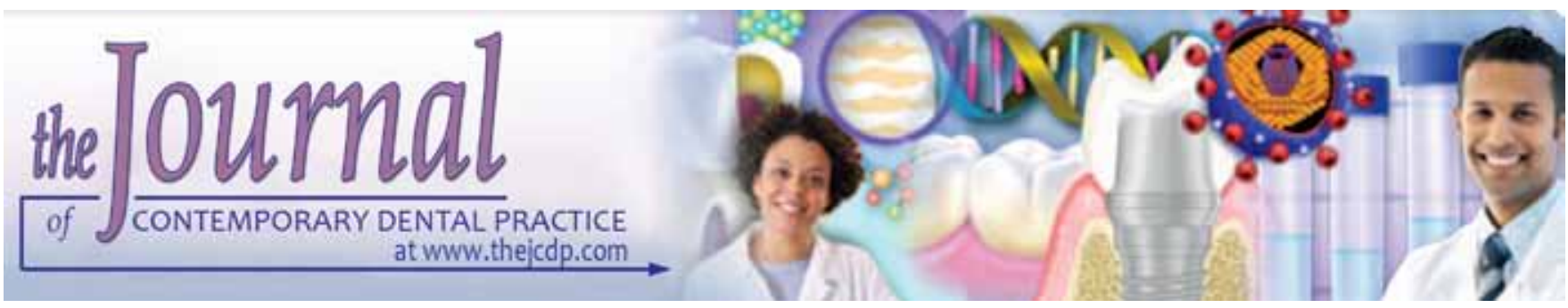

\title{
The Periodontal Status and Associated Systemic Health Problems among an Elderly Population Attending the Outpatient Clinics of a Dental School
}

\author{
Mohammed Jafer
}

\begin{abstract}
Aim: Periodontal diseases are associated with systemic health and health behaviors; the purpose of this study was to investigate periodontal health status and its association with systemic health and health behaviors in the elderly.

Materials and methods: Data was collected from 300 random Case Western Reserve University (CWRU) dental school patient charts, aged 65 or higher. A modified WHO form was used to collect the date on: periodontal conditions using the community periodontal index (CPI), demographics, systemic health and certain health behaviors. Community periodontal index collected data for six sextants. Descriptive tests and bivariate analytic tests, Chi-square test and computation of odds ratio, investigated any association between certain periodontal conditions and demographic as well as systemic health attributes.
\end{abstract}

Results: In the study cohort, the average age was $73.7 \pm 6.8$ years. Moderate periodontitis $(38.9 \%)$ was the most prevalent periodontal health condition, while severe periodontitis was the least prevalent periodontal health $(6.1 \%)$. Nearly $30 \%$ of the cohort had healthy periodontium. Only insurance status was associated with healthy periodontium $(p<0.05)$.

Conclusion: Moderate periodontitis was the most prevalent among the studied subjects. A positive association was found with the insurance status of the subjects and the healthy periodontium. No association was found between periodontal disease and smoking, alcohol consumption, diabetes and cardiovascular disease.

Keywords: Dental insurance, Epidemiology, Periodontal disease, Smoking, Systemic health.

Department of Preventive Dental Sciences, College of Dentistry Jazan University, Jazan, Saudi Arabia

Corresponding Author: Mohammed Jafer, Lecturer and Head Department of Preventive Dental Sciences, College of Dentistry Jazan University, PO Box 114, Jazan, Saudi Arabia, e-mail: maj65@case.edu
How to cite this article: Jafer M. The Periodontal Status and Associated Systemic Health Problems among an Elderly Population Attending the Outpatient Clinics of a Dental School. J Contemp Dent Pract 2015;16(12):950-956.

Source of support: Nil

Conflict of interest: None

\section{INTRODUCTION}

Periodontal diseases are serious chronic infections that involve destruction of the tooth-supporting apparatus, including the gingiva, the periodontal ligament, and alveolar bone. Robust studies have shown that periodontal disease, is significantly associated with certain systemic diseases such as cardiovascular disease, diabetes and complications of diabetes, adverse pregnancy outcomes and respiratory infections. ${ }^{1,2}$ Basic clinical measurements for periodontitis are gingival bleeding on probing, clinical attachment loss, and pocket depths accompanied by radiographic bone loss. ${ }^{3}$ Literature is abundant on the epidemiology of periodontal disease and its associated risk factors; however, the lack of consistency of ascertains periodontitis severity and diagnosis limits precise global comparisons of disease status. ${ }^{4}$ Many international studies have used the World Health Organization's community periodontal index (CPI) to investigate periodontitis prevalence and severity. ${ }^{5}$ Previous findings from the 1980 's and 1990's have estimated severe periodontitis prevalence, ranging from 5 to $15 \%$. There is a lack of recent data on global periodontitis prevalence either confirming or refuting these previous findings. ${ }^{5-7}$

National health and nutrition examination surveys (NHANES), 1999 to 2004, reported that $27.4 \%$ of people from 55 to 74 had periodontitis and that $18.9 \%$ of these people exhibited CPI codes of three. The previously mentioned NHANES studies reported that $14.3 \%$ of individuals from the ages of 65 to 74 had periodontitis. ${ }^{8}$ 
National health and nutrition examination surveys, 2009 to 2010 found that $70.1 \%$ of individuals, aged 65 and older, had periodontitis and $64 \%$ of those individuals showed either moderate or severe forms of the disease. ${ }^{9}$ Studies have also shown that periodontal treatment need is higher in men than it is in women. 9,10 Periodontitis was also higher in individuals below $100 \%$ poverty level. Mexican Americans had higher prevalence of severe periodontitis (17.3\%) than Blacks (6.3\%) and Whites (13.2\%). ${ }^{9}$

Periodontitis is associated with systemic diseases, including: kidney diseases, coronary heart disease, cerebrovascular disease, atherosclerosis, thromboembolic events, dyslipidemia, systemic inflammation and endotoxemia. ${ }^{10-15}$ The prevalence of periodontitis in individuals with coronary artery disease (CAD) was found to be significantly higher. ${ }^{16}$ Periodontitis has also been linked to susceptibility to infectious disease and allows the growth of bacterium in the body. ${ }^{11,17}$ Treatment of periodontitis has shown to reduce the risk of cardiovascular disease. ${ }^{15}$ Moreover, it has been shown that there is an association between periodontitis prevalence and obesity and stress, and an inverse relationship between physical activity and periodontitis risk. ${ }^{12,18-20}$ Nearly $58 \%$ of diabetic patients showed signs of periodontitis compare to $15.0 \%$ without. Smoking and insufficient oral hygiene practice increased the risk of periodontal disease in diabetic patients. ${ }^{21}$ More an individual smokes, he or she is likely to develop more severe forms of periodontitis. ${ }^{22}$ Increases in alcohol intake were associated with increased periodontitis severity in a cross-sectional study. ${ }^{23}$

Study using CPI, found that $83.5 \%$ of the diabetics in the study group had periodontitis and concluded that periodontitis prevalence is higher in diabetic patients than in nondiabetic patients. ${ }^{21,24} \mathrm{~A}$ cross-sectional study found that periodontitis is more common in diabetic than in nondiabetic, but the study also found that this association decreases as an individual ages. ${ }^{25}$ They also found that approximately $30 \%$ of both diabetic and nondiabetic patients with medicare had periodontitis. Approximately $40 \%$ of diabetics with individual, commercial or government insurance exhibited periodontitis. Periodontitis prevalence was approximately $38 \%$ for nondiabetics with individual insurance, and $32 \%$ for nondiabetics with commercial insurance or government insurance. ${ }^{25}$ The purpose of this study was to investigate periodontal health status and its association with systemic health and health behaviors in the elderly population who attended the outpatients' clinics of Case Western University dental department.

\section{MATERIALS AND METHODS}

The Case Western Reserve University (CWRU) Institutional review Board (IRB) approved the protection of human subjects for this research. Recent and updated data was collected from 300 random CWRU dental school patient charts, aged 65 or higher. A modified WHO form was used to collect data on periodontal conditions using the CPI, teeth retention, demographics, systemic health and health behavior. ${ }^{26}$ Index teeth $11,16 / 17,26 / 27,31$, $36 / 37$, and $46 / 47$, representing each of the six sextants of maxillary and mandibular jaw was examined. The examination of an index tooth represented periodontal health of each sextant. The highest CPI code was recorded in each application segment (0: no periodontal disease, 1 : gingival bleeding, 2: supragingival or subgingival calculus, 3: 4-5 mm deep pockets, 4: $6 \mathrm{~mm}$ or deeper pockets). Moderate periodontits was depicted by code 3 and severe periodontitis by code 4 .

The descriptive phase of the analysis counted all periodontal conditions of the same likeness to compute individual CPI scores, and computed the frequency distribution of categorical variables. We used multiple reasons options in statistical package for the social science (SPSS) to investigate the number of cases in each category of CPI. The analytic phase included Chi-square tests and computation of odds ratio, both of which investigated any association between different periodontal conditions and demographic, health behavior and systemic health attributes. Because, the majority of the study cohorts were Caucasians and African-Americans, the study only used these two groups to investigate any ethnic variation. Alpha was set at less than or equal to 0.05 , to determine significance levels of the analytical tests.

\section{RESULTS}

The study sample's average age was $73.7 \pm 6.8$ years, with the mean number of teeth retained at $17.5 \pm 9.9$. The cohort contained more Caucasians (49.3\%), than African-Americans (42.3\%), 8.4\% of the cohort identified as other. All individuals in the cohort had some form of health insurance; $70.3 \%$ of them had private insurance. Respectively, 7.1 and $28.3 \%$ of the study cohort smoked or consumed alcohol. Type II diabetics made up $23.8 \%$ of diabetic patients in the cohort. Most of the cohort (69\%) had cardiovascular diseases (Table 1).

The prevalence of different periodontal conditions in the study sample is depicted in Graph 1 . Nearly 30\% of the cohort exhibited healthy periodontium. Moderate periodontits was found in more members of the cohort (nearly 39\%), which was higher than the other investigated periodontal conditions. Severe periodontitis was the least found periodontal condition investigated in the study $(6.1 \%)$.

Table 2 shows that moderate periodontitis had the highest prevalence among subgroups in the present 
Table 1: Demographic data, systemic health and health behavior in the study population

\begin{tabular}{lll}
\hline Demographic (N) & & Mean $\pm S D$ \\
\hline Age (300) & & $73.7 \pm 6.8$ \\
Number of Teeth (296) & & $17.5 \pm 9.9$ \\
& & Percentage \\
Gender (300) & Male & 41.3 \\
& Female & 58.7 \\
Race (300) & White & 49.3 \\
& Black & 42.3 \\
Insurance (300) & Other & 8.4 \\
& Public & 29.7 \\
Health behavior & Private & 70.3 \\
Smoking (295) & & \\
& Yes & 7.1 \\
Alcohol (293) & No & 92.9 \\
& Yes & 28.3 \\
Systemic health & No & 71.7 \\
Diabetes (294) & & \\
& No & 75.5 \\
& Type I & 0.7 \\
Cardiovascular & Type II & 23.8 \\
disease (297) & Yes & 69 \\
\hline & No & 31 \\
\hline
\end{tabular}

study. Nonsmokers were the highest subgroup (28\%) with healthy periodontium. Among severe periodontal conditions, individuals with cardiovascular disease (23\%) were much more prevalent than those with no cardiovascular disease (7\%). However, this difference was not as large in moderate periodontitis; $59 \%$ of individuals with cardiovascular disease and $53 \%$ of individuals without cardiovascular disease had moderate periodontitis.

Among the demographic, health behavior and systemic health attributes, only insurance status was significantly associated with healthy periodontium. Individual with public insurance were two times more likely to have healthy periodontium $(\mathrm{OR}=2.0,95 \% \mathrm{CI}=1.0,4.1)$ (Table 3). However, all other periodontal conditions showed no

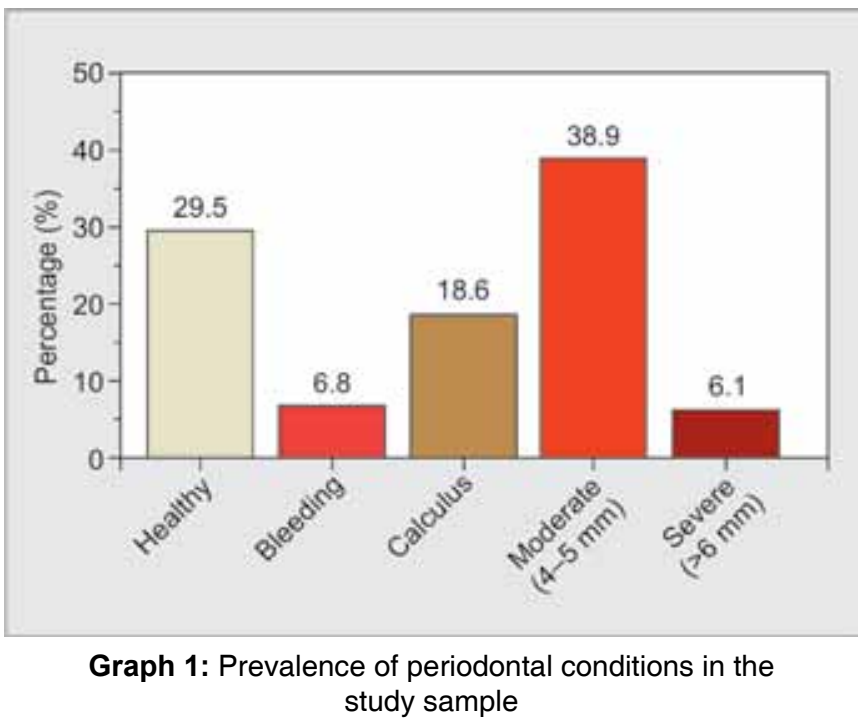

significant association with demographic, health behavior or systemic health attributes (Tables 4 to 7 ).

Table 8 shows the ethnic variations of certain systemic diseases and health behaviors. Whites were 1.8 times more likely to have cardiovascular disease compared to Blacks in the sample ( $\mathrm{OR}=1.79,95 \% \mathrm{CI}=1.1,2.3)$. Smoking, alcohol and diabetes did not show any significant ethnic variation.

\section{DISCUSSION}

Oral health is an integral component of general health and well-being of an individual. Increasing evidence is available indicating periodontitis as a risk factor for various systemic diseases. ${ }^{27,28}$ During the last few decades, many cross-sectional and longitudinal epidemiological studies on the prevalence and severity of periodontal disease in adults have been performed. There is still a lack of agreement on what kind of criteria should be used in epidemiological studies. ${ }^{29}$ A further difficulty is the lack of well-defined criteria which makes it impossible

Table 2: Prevalence of periodontal conditions in the demographic and systemic health/health behavior attributes

\begin{tabular}{|c|c|c|c|c|c|c|}
\hline Factors (\%) & & Healthy & Bleeding & Calculus & Moderate periodontitis & Severe periodontitis \\
\hline \multirow[t]{2}{*}{ Gender } & Male & 13 & 14 & 35 & 57 & 27 \\
\hline & Female & 17 & 21 & 41 & 56 & 11 \\
\hline \multirow[t]{2}{*}{ Race } & Whites & 18 & 15 & 35 & 52 & 14 \\
\hline & Blacks & 11 & 24 & 46 & 64 & 21 \\
\hline \multirow[t]{2}{*}{ Insurance } & Public & 5 & 37 & 43 & 68 & 29 \\
\hline & Private & 24 & 15 & 38 & 54 & 15 \\
\hline \multirow[t]{2}{*}{ Smoking } & No & 28 & 18 & 39 & 57 & 15 \\
\hline & Yes & 2 & 20 & 20 & 56 & 33 \\
\hline \multirow[t]{2}{*}{ Alcohol } & No & 20 & 19 & 39 & 57 & 14 \\
\hline & Yes & 10 & 15 & 36 & 57 & 21 \\
\hline \multirow[t]{2}{*}{ Diabetes } & No & 24 & 20 & 38 & 55 & 16 \\
\hline & Yes & 6 & 13 & 42 & 59 & 22 \\
\hline \multirow[t]{2}{*}{ CVD } & No & 11 & 16 & 36 & 53 & 7 \\
\hline & Yes & 18 & 20 & 41 & 59 & 23 \\
\hline
\end{tabular}


The Periodontal Status and Associated Systemic Health Problems among an Elderly Population

Table 3: Association between gingival bleeding and demographic and systemic health/health behavior attributes

\begin{tabular}{|c|c|c|c|c|c|c|}
\hline \multirow{3}{*}{ Demographic } & & \multicolumn{2}{|c|}{ Prevalence } & \multirow[b]{2}{*}{ OR } & \multirow{2}{*}{\multicolumn{2}{|c|}{$95 \% \mathrm{Cl}$}} \\
\hline & & \multirow[t]{2}{*}{ Yes } & \multirow[t]{2}{*}{ No } & & & \\
\hline & & & & 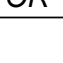 & \multicolumn{2}{|c|}{$95 \%$ Cl } \\
\hline \multirow[t]{2}{*}{ Gender } & Male & 93 & 5 & 1.5 & 0.5 & 4.6 \\
\hline & Female & 133 & 11 & & & \\
\hline \multirow[t]{2}{*}{ Race } & White & 111 & 8 & 1.2 & 0.4 & 3.2 \\
\hline & Black & 96 & 8 & & & \\
\hline \multirow[t]{2}{*}{ Insurance } & Public & 67 & 7 & 0.6 & 0.2 & 1.7 \\
\hline & Private & 158 & 10 & & & \\
\hline \multicolumn{7}{|l|}{ Health behavior } \\
\hline \multirow{2}{*}{ Smoking } & Yes & 16 & 1 & 1.2 & 0.1 & 9.3 \\
\hline & No & 208 & 15 & & & \\
\hline \multirow[t]{2}{*}{ Alcohol } & Yes & 63 & 4 & 1.1 & 0.3 & 3.5 \\
\hline & No & 161 & 11 & & & \\
\hline \multicolumn{7}{|l|}{ Systemic health } \\
\hline \multirow[t]{2}{*}{ Diabetes } & Type II & 53 & 2 & 2.2 & 0.5 & 10.1 \\
\hline & No & 167 & 14 & & & \\
\hline \multirow{2}{*}{$\begin{array}{l}\text { Cardiovascular } \\
\text { disease }\end{array}$} & Yes & 155 & 11 & 1.0 & 0.3 & 3.0 \\
\hline & No & 70 & 5 & & & \\
\hline
\end{tabular}

Table 5: Association between calculus and demographic and systemic health/health behavior attributes

\begin{tabular}{|c|c|c|c|c|c|c|}
\hline & \multicolumn{2}{|c|}{ Prevalence } & \multirow[b]{2}{*}{ OR } & \multirow{2}{*}{\multicolumn{2}{|c|}{$95 \% \mathrm{Cl}$}} \\
\hline & & Yes & No & & & \\
\hline \multicolumn{7}{|l|}{ Demographic } \\
\hline \multirow[t]{2}{*}{ Gender } & Male & 81 & 17 & 1.2 & 0.6 & 2.2 \\
\hline & Female & 116 & 28 & & & \\
\hline \multirow[t]{2}{*}{ Race } & White & 97 & 24 & 1.07 & 0.6 & 2.0 \\
\hline & Black & 83 & 22 & & & \\
\hline \multirow[t]{2}{*}{ Insurance } & Public & 59 & 9 & 1.7 & 0.7 & 3.6 \\
\hline & Private & 139 & 35 & & & \\
\hline \multicolumn{7}{|l|}{ Health behavior } \\
\hline \multirow[t]{2}{*}{ Smoking } & Yes & 14 & 1 & 3.3 & 0.4 & 25.8 \\
\hline & No & 182 & 43 & & & \\
\hline \multirow[t]{2}{*}{ Alcohol } & Yes & 55 & 13 & 0.9 & 0.5 & 1.9 \\
\hline & No & 140 & 31 & & & \\
\hline \multicolumn{7}{|l|}{ Systemic health } \\
\hline \multirow[t]{2}{*}{ Diabetes } & Type II & 46 & 10 & 1.1 & 0.5 & 2.4 \\
\hline & No & 145 & 35 & & & \\
\hline \multirow{2}{*}{$\begin{array}{l}\text { Cardiovascular } \\
\text { disease }\end{array}$} & Yes & 135 & 30 & 1.1 & 0.6 & 2.2 \\
\hline & No & 61 & 15 & & & \\
\hline
\end{tabular}

in the majority of studies to differ between extent and severity of periodontal disease. A lack of universal criteria for ascertaining periodontal disease studies has left ambiguity in the definition of periodontitis. ${ }^{4,7}$ This lack of uniformity may limit precise comparisons of odds ratio between periodontal studies. ${ }^{30}$ Different periodontal indexes have been used to assess periodontal disease. Because of the convenience of CPI in epidemiological settings, it has been widely used in international studies for many years. ${ }^{31}$ Several studies have questioned the validity of CPI as an accurate predictor of periodontal health conditions. ${ }^{32-34}$ Other studies have suggested that
Table 4: Association between healthy periodontal condition and demographic and systemic health/health behavior attributes

\begin{tabular}{|c|c|c|c|c|c|c|}
\hline & \multicolumn{2}{|c|}{ Prevalence } & \multirow[b]{2}{*}{ OR } & \multirow{2}{*}{\multicolumn{2}{|c|}{$95 \% \mathrm{Cl}$}} \\
\hline & & Yes & No & & & \\
\hline \multicolumn{7}{|l|}{ Demographic } \\
\hline \multirow[t]{2}{*}{ Gender } & Male & 70 & 31 & 0.9 & 0.5 & 1.6 \\
\hline & Female & 100 & 41 & & & \\
\hline \multirow[t]{2}{*}{ Race } & White & 85 & 44 & 0.7 & 0.4 & 1.2 \\
\hline & Black & 73 & 26 & & & \\
\hline \multirow[t]{2}{*}{ Insurance } & Public & 51 & 12 & 2.0 & 1.0 & 4.1 \\
\hline & Private & 121 & 58 & & & \\
\hline \multicolumn{7}{|l|}{ Health behavior } \\
\hline \multirow[t]{2}{*}{ Smoking } & Yes & 12 & 4 & 1.1 & 0.4 & 3.6 \\
\hline & No & 157 & 67 & & & \\
\hline \multirow[t]{2}{*}{ Alcohol } & Yes & 48 & 23 & 0.8 & 0.5 & 1.5 \\
\hline & No & 120 & 48 & & & \\
\hline \multicolumn{7}{|l|}{ Systemic health } \\
\hline \multirow[t]{2}{*}{ Diabetes } & Type II & 40 & 14 & 1.3 & 0.7 & 2.6 \\
\hline & No & 125 & 57 & & & \\
\hline \multirow{2}{*}{$\begin{array}{l}\text { Cardiovascular } \\
\text { disease }\end{array}$} & Yes & 117 & 44 & 1.4 & 0.8 & 2.4 \\
\hline & No & 53 & 27 & & & \\
\hline
\end{tabular}

Table 6: Association between moderate periodontitis and demographic and systemic health/health behavior attributes

\begin{tabular}{|c|c|c|c|c|c|c|}
\hline & \multicolumn{2}{|c|}{ Prevalence } & \multirow[b]{2}{*}{ OR } & \multirow{2}{*}{\multicolumn{2}{|c|}{$95 \% \mathrm{Cl}$}} \\
\hline & & Yes & No & & & \\
\hline \multicolumn{7}{|l|}{ Demographic } \\
\hline \multirow[t]{2}{*}{ Gender } & Male & 61 & 41 & 0.9 & 0.5 & 1.5 \\
\hline & Female & 87 & 53 & & & \\
\hline \multirow[t]{2}{*}{ Race } & White & 72 & 48 & 1.1 & 0.7 & 1.9 \\
\hline & Black & 62 & 47 & & & \\
\hline \multirow[t]{2}{*}{ Insurance } & Public & 44 & 26 & 1.1 & 0.6 & 2.0 \\
\hline & Private & 104 & 68 & & & \\
\hline \multicolumn{7}{|l|}{ Health behavior } \\
\hline \multirow[t]{2}{*}{ Smoking } & Yes & 10 & 5 & 1.3 & 0.4 & 3.9 \\
\hline & No & 137 & 88 & & & \\
\hline \multirow[t]{2}{*}{ Alcohol } & Yes & 41 & 30 & 0.8 & 0.5 & 1.5 \\
\hline & No & 104 & 64 & & & \\
\hline \multicolumn{7}{|l|}{ Systemic health } \\
\hline \multirow[t]{2}{*}{ Diabetes } & Type II & 35 & 20 & 1.1 & 0.6 & 2.1 \\
\hline & No & 110 & 71 & & & \\
\hline \multirow{2}{*}{$\begin{array}{l}\text { Cardiovascular } \\
\text { disease }\end{array}$} & Yes & 101 & 63 & 1.1 & 0.6 & 1.9 \\
\hline & No & 45 & 31 & & & \\
\hline
\end{tabular}

CPI may underestimate the severity of periodontitis and that the index may not be reliable for epidemiological assessments. ${ }^{35}$ The cross-sectional nature of the present study does not consider changes in periodontal health over extended periods. Furthermore, patient charts used in the present study were completed by dental students who received uniform didactic education, but were not clinically calibrated. Diagnosis and treatment planning may also vary due to differences in practice of supervising preceptors.

The prevalence rate of moderate and severe periodontitis was $19 \%$ less in the present study ( $45 \%$ ) than 
Table 7: Association between severe periodontitis and demographic and systemic health/health behavior attributes

\begin{tabular}{|c|c|c|c|c|c|c|}
\hline & \multicolumn{2}{|c|}{ Prevalence } & \multirow[b]{2}{*}{ OR } & \multirow{2}{*}{\multicolumn{2}{|c|}{$95 \% \mathrm{Cl}$}} \\
\hline & & Yes & No & & & \\
\hline \multicolumn{7}{|l|}{ Demographic } \\
\hline \multirow[t]{2}{*}{ Gender } & Male & 94 & 9 & 0.4 & 0.1 & 1.2 \\
\hline & Female & 134 & 5 & & & \\
\hline \multirow[t]{2}{*}{ Race } & White & 112 & 7 & 1.2 & 0.3 & 3.4 \\
\hline & Black & 96 & 7 & & & \\
\hline \multirow[t]{2}{*}{ Insurance } & Public & 67 & 5 & 0.8 & 0.3 & 2.5 \\
\hline & Private & 160 & 10 & & & \\
\hline \multicolumn{7}{|l|}{ Health behavior } \\
\hline \multirow[t]{2}{*}{ Smoking } & Yes & 16 & 2 & 0.5 & 0.1 & 2.2 \\
\hline & No & 210 & 12 & & & \\
\hline \multirow[t]{2}{*}{ Alcohol } & Yes & 64 & 6 & 0.5 & 0.2 & 1.6 \\
\hline & No & 161 & 8 & & & \\
\hline \multicolumn{7}{|l|}{ Systemic health } \\
\hline \multirow[t]{2}{*}{ Diabetes } & Type II & 53 & 4 & 0.9 & 0.3 & 2.8 \\
\hline & No & 168 & 11 & & & \\
\hline \multirow{2}{*}{$\begin{array}{l}\text { Cardiovascular } \\
\text { disease }\end{array}$} & Yes & 156 & 13 & 0.3 & 0.1 & 1.6 \\
\hline & No & 70 & 2 & & & \\
\hline
\end{tabular}

the national level (64\%). National health and nutrition examination surveys, 2009 to 2010 , reported that $53 \%$ of adults over the age of 65 had moderate periodontitis and $11.2 \%$ of elderly adults had severe periodontitis, ${ }^{9}$ while in the present study moderate and severe periodontitis prevalence was 39 and $6.1 \%$ respectively. Besides the very large difference in sample size and makeup of the sample cohorts, these differences in periodontitis prevalence could be because of the different indexes used to measure periodontitis; the present study used CPI in six defined teeth, while NHANES used attachment loss (AL) and probing depth (PD) for all teeth, except the third molar. ${ }^{9}$ The method used in NHANES, 2009 to 2010, may be a better indicator of periodontitis prevalence. ${ }^{36,37}$

There were differences in case ascertainment of periodontal disease between the two studies. National health and nutrition examination surveys, 2009 to 2010, defined moderate periodontitis as two or more interproximal sites with a PD of at least $5 \mathrm{~mm}$ or AL of at least $4 \mathrm{~mm}$ at two or more interproximal sites. Severe periodontitis was defined as the combination of two interproximal sites with at least $6 \mathrm{~mm} \mathrm{AL}$ and at least one interproximal site with a PD of $5 \mathrm{~mm}$ or deeper. ${ }^{9}$ The present study, only used pocket depth to measure periodontitis severity; Moderate periodontitis was defined as 4 to $5 \mathrm{~mm}$ pocket depth and severe periodontitis was defined as a pocket depth of six or more millimeters.

Previous studies have shown that Caucasians were twice more likely to have a healthy periodontium than African-Americans; these findings were not confirmed in the present study. ${ }^{30,38}$ The present study confirms the previously reported associations between periodontal health and insurance status. ${ }^{21,25,39}$ Even though smokers
Table 8: Association between ethnicity and systemic health/ health behavior attributes

\begin{tabular}{|c|c|c|c|c|c|c|}
\hline \multirow{2}{*}{\multicolumn{2}{|c|}{$\begin{array}{l}\text { Systemic/ } \\
\text { behavior health }\end{array}$}} & \multicolumn{2}{|c|}{ Prevalence } & \multirow[b]{2}{*}{ OR } & \multirow{2}{*}{\multicolumn{2}{|c|}{$95 \% \mathrm{Cl}$}} \\
\hline & & Yes & No & & & \\
\hline \multirow[t]{2}{*}{ Smoking } & Whites & 140 & 7 & 2.1 & 0.82 & 5.34 \\
\hline & Black & 134 & 14 & & & \\
\hline \multirow[t]{2}{*}{ Alcohol } & Whites & 93 & 55 & 0.4 & 0.24 & 0.69 \\
\hline & Black & 117 & 28 & & & \\
\hline \multirow[t]{2}{*}{ Diabetes } & Whites & 114 & 29 & 1.5 & 0.87 & 2.57 \\
\hline & Black & 108 & 41 & & & \\
\hline \multirow{2}{*}{$\begin{array}{l}\text { Cardiovascular } \\
\text { disease }\end{array}$} & Whites & 55 & 93 & 1.8 & 1.09 & 2.95 \\
\hline & Black & 37 & 112 & & & \\
\hline
\end{tabular}

were reported to be more prone to periodontal disease, ${ }^{40,41}$ no association was observed in the present study. This could be because of the low number $(7 \%)$ of individuals who were smokers in the present study.

Studies have shown periodontitis is associated with coronary heart disease as well as cerebrovascular diseases in the general population, ${ }^{11-13}$ which was not confirmed by the present study. These studies focused on certain type of cardiovascular diseases, which were done much earlier than the present study and utilized different age groups. This difference could be due to the makeup of the study sample; the present study did not exclude any types of reported cardiovascular disease from analysis. Approximately 83.6 million US adults have some type of cardiovascular disease (CVD). Of them, 42.2 million $(50.4 \%)$ are 60 years or older. ${ }^{42}$ Cardiovascular disease prevalence in the present study was $69 \%$, which is higher than the national average.

\section{CONCLUSION}

The present study found that of the investigated periodontal health conditions, moderate periodontitis was the most prevalent $(38.9 \%)$ in the study cohort. A positive association was found with the insurance status of the subjects and the healthy periodontium. Further population based studies are required to confirm the association between the periodontitis and systemic health of the population.

\section{ACKNOWLEDGMENT}

The author would like to acknowledge the support given by Dr Sena Narendran and James Lalumandier, Case Western Reserve University, Ohayo, USA.

\section{REFERENCES}

1. Page RC, Offenbacher S, Schroeder HE, Seymour GJ, Kornman KS. Advances in the pathogenesis of periodontitis: summary of developments, clinical implications and future directions. Periodontol 2000, 1997;14(1):216-248. 
2. Kinane DF. Periodontitis modified by systemic factors. Annals Periodontol 1999;4(1):54-63.

3. Plancak D, Jorgic-Srdjak K, Curilovic Z. New classification of periodontal diseases. Acta Stomat Croat 2001;35(1):89-93.

4. Savage A, Eaton KA, Moles DR, Needleman I. A systematic review of definitions of periodontitis and methods that have been used to identify this disease. J Clin Periodontol 2009;36 (6):458-467.

5. Albandar JM, Rams TE. Global epidemiology of periodontal diseases: an overview. Periodontol 2000, 2002;29(1):7-10.

6. Pilot T, Miyazaki H, Leclercq MH, Barmes DE. Profiles of periodontal conditions in older age cohorts, measured by CPITN. Int Dent J 1992;42(1):23-30.

7. Papapanou PN. Periodontal diseases: epidemiology. Ann Periodontol 1996;1(1):1-36.

8. Dye BA, Tan S, Smith V, Lewis B, Barker L, Thornton-Evans G, et al. Trends in oral health status: United States, 1988-1994 and 1999-2004. Vital and health statistics. Series 11, Data from the national health survey 2007(248):1-92.

9. Eke PI, Dye BA, Wei L, Thornton-Evans GO, Genco RJ, Cdc Periodontal disease surveillance workgroup: James Beck GDRP. Prevalence of periodontitis in adults in the United States: 2009 and 2010. J Dent Res 2012;91(10):914-920.

10. Ajwani S, Tervonen T, Närhi TO, Ainamo A. Periodontal health status and treatment needs among the elderly. Special Care in Dentist 2001;21(3):98-103.

11. Ajwani S, Mattila KJ, Tilvis RS, Ainamo A. Periodontal disease and mortality in an aged population. Spec Care Dentist 2003;23(4):125-130.

12. Stenvinkel $P$, Carrero JJ, Axelsson J, Lindholm B, Heimbürger O, Massy Z. Emerging biomarkers for evaluating cardiovascular risk in the chronic kidney disease patient: how do new pieces fit into the uremic puzzle? Clin J Am Society of Nephrol 2008; 3(2):505-521.

13. Grau AJ, Buggle F, Ziegler C, Schwarz W, Meuser J, Tasman A-J, et al. Association between acute cerebrovascular ischemia and chronic and recurrent infection. Stroke 1997;28(9):1724-1729.

14. Vettore MV. Periodontal disease and cardiovascular disease. Evid Based Dent 2004;5(3):69.

15. Humphrey LL, Fu R, Buckley DI, Freeman M, Helfand M. Periodontal disease and coronary heart disease incidence: a systematic review and meta-analysis. J Gen Intern Med 2008;23(12):2079-2086.

16. Al-Zahrani MS, Kayal RA, Bissada NF. Periodontitis and cardiovascular disease: a review of shared risk factors and new findings supporting a causality hypothesis. Quintessence Int 2006;37(1):11-18.

17. Lin S-Y, Lin C-L, Liu J-H, Wang I-K, Hsu W-H, Chen C-J, et al. Association between periodontitis needing surgical treatment and subsequent diabetes risk: a population-based cohort study. J Periodontol 2014;85(6):779-786.

18. Al-Zahrani MS, Bissada NF, Borawskit EA. Obesity and periodontal disease in young, middle-aged and older adults. J Periodontol 2003;74(5):610-615.

19. Chaffee BW, Weston SJ. Association between chronic periodontal disease and obesity: a systematic review and meta-analysis. J Periodontol 2010;81(12):1708-1724.

20. Merchant AT, Pitiphat W, Rimm EB, Joshipura K. Increased physical activity decreases periodontitis risk in men. Eur J Epidemiol 2003;18(9):891-898.
21. Popławska-Kita A, Siewko K, Szpak P, Król B, Telejko B, Klimiuk PA, et al. Association between type 1 diabetes and periodontal health. Advances in Medical Sci 2014;59(1): 126-131.

22. Genco RJ. Current view of risk factors for periodontal diseases. J Periodontol 1996;67(10 Suppl):1041-1049.

23. Tezal M, Grossi SG, Ho AW, Genco RJ. Alcohol consumption and periodontal disease. The Third National Health and Nutrition Examination Survey. J Clin Periodontol 2004;31(7): 484-488.

24. Poplawska-Kita A, Siewko K, Szpak P, Krol B, Telejko B, Klimiuk PA, et al. Relationship between type 2 diabetes and periodontal health. Prog Health Sci 2013;2(3):137-144.

25. Newton KM, Chaudhari M, Barlow WE, Inge RE, Theis MK, Spangler LA, et al. A population-based study of periodontal care among those with and without diabetes. J Periodontol 2011;82(12):1650-1656.

26. WHO. Oral health surveys: basic methods; World Health Organization: World Health Organization; 1987.

27. Scannapieco FA, Dasanayake AP, Chhun N. Does periodontal therapy reduce the risk for systemic diseases? Dent Clin North America 2010;54(1):163-181.

28. Cullinan M, Ford P, Seymour G. Periodontal disease and systemic health: current status. Australian Dent J 2009; 54(s1):S62-S69.

29. Hugoson A, Norderyd O. Has the prevalence of periodontitis changed during the last 30 years? J Clin Periodontol 2008; 35(s8):338-345.

30. Borrell LN, Papapanou PN. Analytical epidemiology of periodontitis. J Clin Periodontol 2005;32 Suppl 6(s6):132-158.

31. Benigeri M, Brodeur JM, Payette M, Charbonneau A, Ismail AI. Community periodontal index of treatment needs and prevalence of periodontal conditions. J Clin Periodontol 2000; 27(5):308-312.

32. Lewis JM, Morgan MV, Wright FA. The validity of the CPITN scoring and presentation method for measuring periodontal conditions. J Clin Periodontol 1994;21(1):1-6.

33. Takahashi Y, Kamijyo H, Kawanishi S, Takaesu Y. Presence and absence of bleeding in association with calculus in segments given code 2 in the community periodontal index of treatment needs (CPITN). Community Dent Oral Epidemiol 1988;16(2):109-111.

34. Grytten J, Holst D, Gjermo P. Validity of CPITN's hierarchical scoring method for describing the prevalence of periodontal conditions. Community Dent Oral Epidemiol 1989;17(6): 300-303.

35. Gera I. Periodontal treatment needs in central and eastern Europe. J Int Acad Periodontol 2000;2(4):120-128.

36. Albandar JM, Brunelle JA, Kingman A. Destructive periodontal disease in adults 30 years of age and older in the United States, 1988-1994. J Periodontol 1999;70(1):13-29.

37. Kingman A, Albandar JM. Methodological aspects of epidemiological studies of periodontal diseases. Periodontol 2000; 2002;29(1):11-30.

38. Borrell LN, Taylor GW, Borgnakke WS, Nyquist LV, Woolfolk MW, Allen DJ, et al. Factors influencing the effect of race on established periodontitis prevalence. J Public Health Dent 2003;63(1):20-29.

39. Leite RS, Marlow NM, Fernandes JK. Oral health and type 2 diabetes. Am J Med Sci 2013;345(4):271-273. 
40. Linden GJ, Mullally BH. Cigarette smoking and periodontal destruction in young adults. J Periodontol 1994;65(7):718-723.

41. GrossiSG,ZambonJJ,HoAW,KochG,Dunford RG,MachteiEE, et al. Assessment of risk for periodontal disease. I. Risk indicators for attachment loss. J Periodontol 1994;65(3):260-267.

42. Goff DC Jr, Brass L, Braun LT, Croft JB, Flesch JD, Fowkes FG, et al. Essential features of a surveillance system to support the prevention and management of heart disease and stroke: a scientific statement from the American Heart Association Councils on epidemiology and prevention, stroke, and cardiovascular nursing and the interdisciplinary working groups on quality of care and outcomes research and atherosclerotic peripheral vascular disease. Circulation 2007;115(1):127-155. 